\title{
Cluster Development Test 2 an Assessment of a Failed Test
}

\author{
Ricardo A. Machin ${ }^{1}$ and Carol T. Evans ${ }^{2}$ \\ National Aeronautics and Space Administration \\ Johnson Space Center, Houston, TX
}

\begin{abstract}
On 31 July 2008 the National Aeronautics and Space Administration Crew Exploration Vehicle Parachute Assembly System team conducted the final planned cluster test of the first generation parachute recovery system design. The two primary test objectives were to demonstrate the operation of the complete parachute system deployed from a full scale capsule simulator and to demonstrate the test technique of separating the capsule simulator from the Low Velocity Air Drop pallet used to extract the test article from a United States Air Force C-17 aircraft. The capsule simulator was the Parachute Test Vehicle with an accurate heat shield outer mold line and forward bay compartment of the Crew Exploration Vehicle Command Module. The Parachute Test Vehicle separated cleanly from the pallet following extraction, but failed to reach test conditions resulting in the failure of the test and the loss of the test assets. No personnel were injured. This paper will discuss the design of the test and the findings of the team that investigated the test, including a discussion of what were determined to be the root causes of the failure.
\end{abstract}

\section{Introduction}

$\mathrm{T}$ HE Crew Exploration Vehicle (CEV) is the next human rated space craft under development for the National Aeronautics and Space Administration (NASA), designed to replace the Space Shuttle for low earth orbit missions. The CEV will be a capsule that uses a parachute system to decelerate and safely land the crew, similar to Apollo only larger. The CEV Parachute Assembly System (CPAS) is a Government Furnished Equipment (GFE) project led by the Johnson Space Center (JSC) responsible for the development, qualification, and delivery of the parachute system that will be used on the first three human flights.

The Generation 1 (Gen-1) CPAS architecture was described in detail at the $19^{\text {th }}$ AIAA Aerodynamic Decelerator Systems conference in $2007^{1}$. The purpose of the Gen-1 design was not only to field and test a parachute recovery system that would meet the stated requirements, but also to develop the relationship between the design and test teams in preparation for the flight design and qualification testing.

\section{The Test Hardware}

Cluster Development Test 2 (CDT-2) was the last planned test of the Gen-1 system. This was the first test to utilize the Parachute Test Vehicle (PTV), a boiler plate of the CEV consisting of an accurate forward bay where the CPAS was rigged, as well as a full scale heat shield to generate the proper wake for the parachutes. Figure 1 shows a comparison of the PTV to the CEV. In order to meet the requirements of the United States Air Force (USAF) for Low Velocity Air Drop (LVAD) test articles, the PTV total height was truncated by XX inches. This was accomplished by maintaining the exact geometry of the forward bay and truncating the back shell of the PTV, this resulted in a shelf at the interface of the back shell to the forward bay that does not exist on the CEV. Wind tunnel tests and computational fluid dynamics (CFD) were performed in order to understand the effects of this change to the Outer Mold Line (OML) on the flow field in the wake of the PTV. The results of this analysis indicated that there ?? differences, if any, were within the predicted accuracy of the techniques. The wind tunnel testing and the CFD also provided aerodynamic data for the PTV which was used in the trajectory analysis.

\footnotetext{
${ }^{1}$ Insert Job Title, Department Name, Address/Mail Stop, and AIAA Member Grade for first author.

${ }^{2}$ Insert Job Title, Department Name, Address/Mail Stop, and AIAA Member Grade for second author.
} 


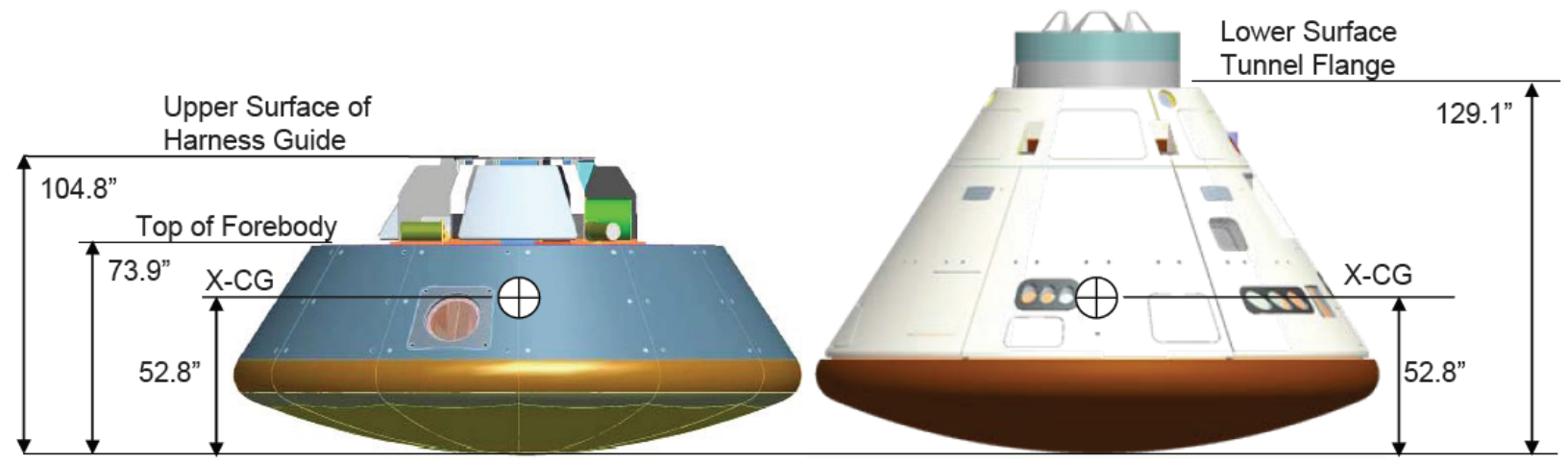

Figure 1. Comparison of PTV and the CEV.

The PTV was rigged to a modified LVAD platform so that it could be extracted from a USAF C-17 aircraft. The CEV PTV Separation System (CPSS) was designed and manufactured by Coleman Engineering under contract to CPAS. There were three penetrations to the heat shield of the PTV that allowed the CPSS to restrain the PTV. Coleman provided the trajectory simulation from extraction through PTV release. The remainder of the PTV trajectory was modeled by the CPAS team using the Decelerator System Simulation ${ }^{2}$. The Coleman contract also included the development and implementation of the parachute recovery system to safely land the CPSS.

\section{Development of the Concept of Operations}

From the concept of operations point of view the test was broken into four phases: 1) extraction through PTV release, 2) the programmer phase where the PTV was stabilized and delivered to the CPAS deployment test point, 3) the CPAS test sequence itself through to landing the PTV, and 4) the recovery of the CPSS.

\section{A. Extraction through PTV Release}

The purpose of the CPSS was to restrain the PTV during extraction and release it such that the programmer phase could safely commence. The modeling of this phase was complicated as it involved not only the extraction of the combined PTV/CPSS out of the C-17, but also included contact forces between the CPSS and the PTV which could impart rates to the PTV as it released. The CPSS was designed to implement a delayed load transfer in order to induce a pitch limit cycle of the combined PTV/CPSS with the extraction parachute still attached to the pallet via the Extraction Force Transfer Coupling (EFTC). This phenomenon of a pitch limit cycle has been observed on other tests that implemented a delayed load transfer and it was felt that it could be accurately modeled in the simulations. The intent was to release the PTV from the CPSS at the first minimum of under rotation that would take place following extraction. Releasing at this first minimum (or inflection point) in the under rotation would provide the best chance of separating the PTV without re-contacting the CPSS. This point in the trajectory also nearly coincides with the lowest dynamic pressure for deploying the programmer parachute, allowing an increase in programmer reefing such that it would remain within the design loads of the attach structure on the top of the PTV. The initial conditions or state vector of the released PTV were taken from the Coleman simulation and handed off to the CPAS trajectory team for deployment of the programmer parachute. Figure 2 shows the PTV rigged to the CPSS prior to loading on the $\mathrm{C}-17$. 


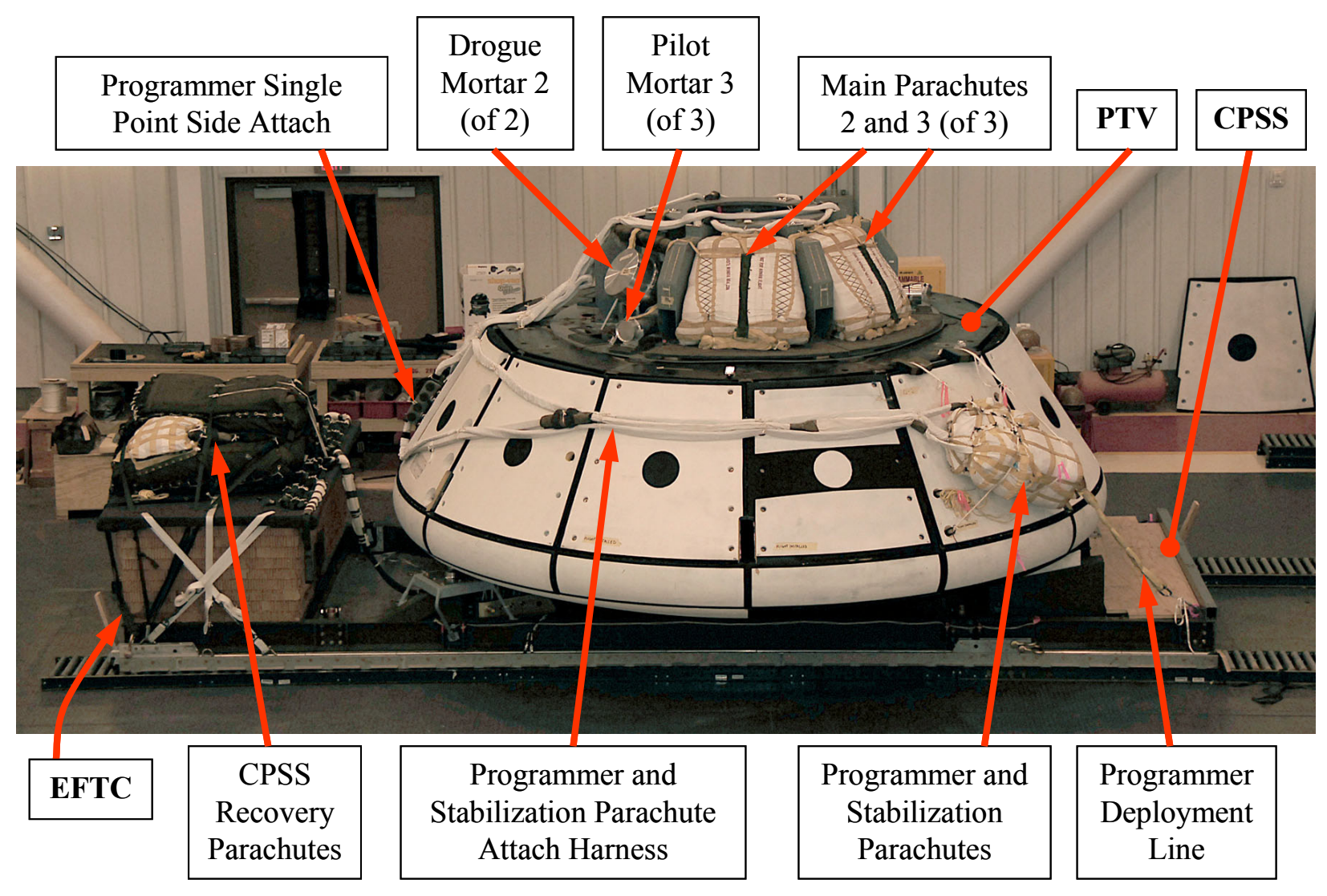

Figure 2. PTV rigged to the CPSS.

\section{B. PTV Programmer Phase}

The purpose of the programmer phase was to stabilize the PTV following release from the CPSS and deliver the PTV to the intended state vector for initiation of the CPAS test sequence. The programmer parachute initially chosen was the Orbiter $40 \mathrm{ft}$ decelerator parachute. This parachute was chosen because it was available without requiring development testing, it had been used as a programmer on prior tests, and it had a relatively large design limit load. After investigating a variety of possible locations for storing the programmer parachute, the decision was made to rig it to the starboard windward shoulder of the PTV (with respect to the PTV/CPSS as extracted from the $\mathrm{C}$-17). The static line for the programmer was anchored to the forward end of the pallet just beneath the programmer was rigged to the PTV.

Early simulations of the PTV free flight once separated from the CPSS indicated that deploying the programmer to a three point attach through the top of the forward bay (much like the main attach) there was a greater than $90 \%$ chance that the PTV would tumble through apex into the wind prior to the programmer parachute inflating. Because the PTV did not have a Forward Bay Cover the risk of damaging the CPAS hardware stored in the forward bay was considered high and it did not seem possible to protect this hardware without interfering with its proper deployment. The two parameters that had the greatest affect on the apex forward tumble were the initial rate of the PTV as it separated from the CPSS and the time delay from PTV release to programmer inflation. The only solution modeled that would stabilize the PTV using the programmer was to have an intermediate attach on the side of the PTV for the programmer. This would result in the PTV flying 'sideways' for six seconds allowing for the dynamics to damp out prior to repositioning the programmer to the intended three point attach on the top of the PTV. While this modification eliminated the apex forward tumbles that would pass through alpha zero, the simulations still indicated that approximately $30 \%$ of the cases would reach an apex forward angle of attack. The addition of stabilization parachutes, deployed with the programmer parachute but which were more closely coupled to the PTV release, drove these apex forward cases to less than $10 \%$. They were subsequently added to the test configuration. The programmer and stabilization parachutes would be released from their three point attach 30 seconds after PTV release. Figure 3 depicts the test sequence for the extraction and programmer phases. The wake effect on the 
performance of the programmer and stabilization parachutes was estimated by taking the available wind tunnel and CFD data, both of which represented a time average wake deficit.

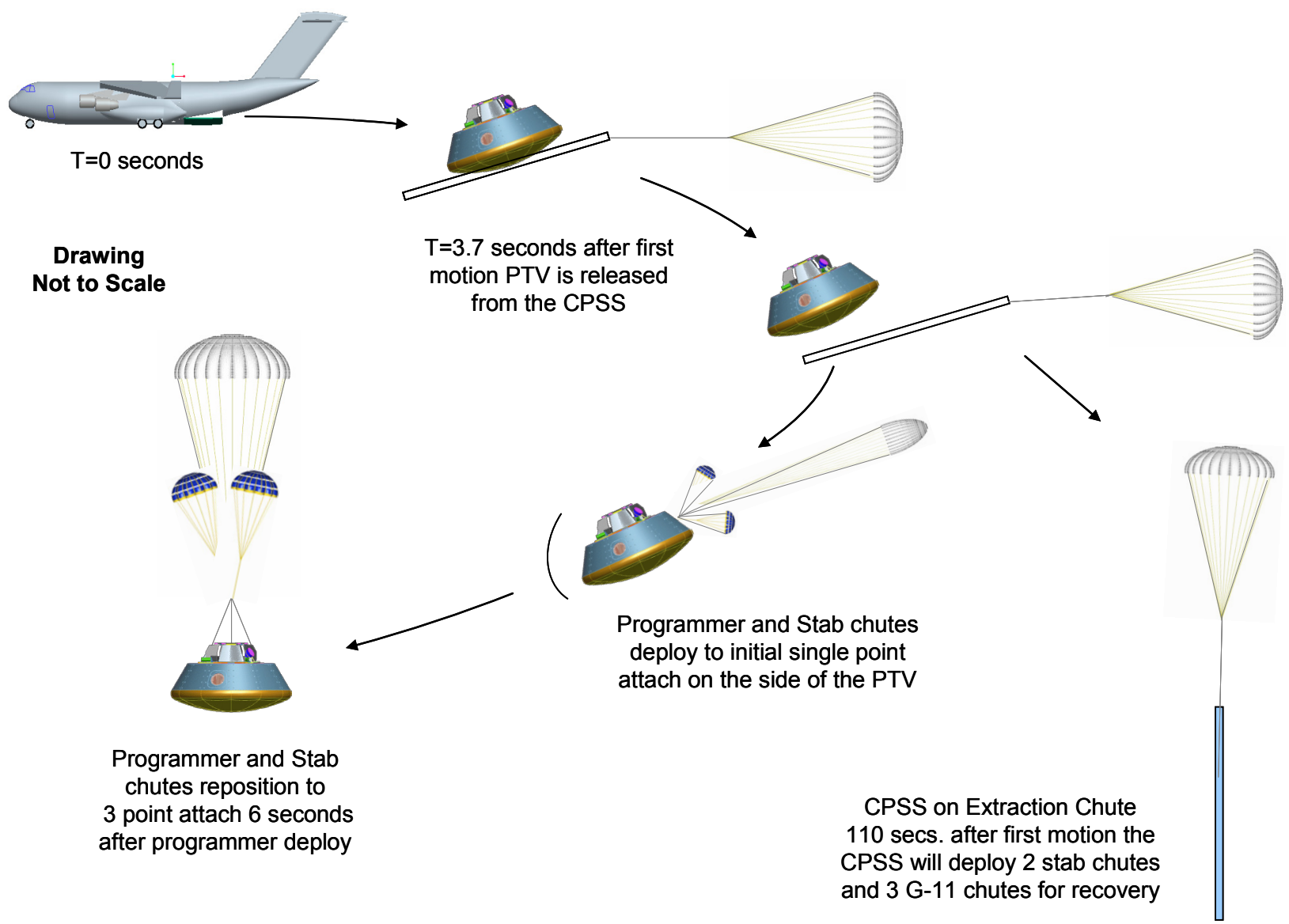

Figure 3. Concept of Operations: Extraction through Programmer Reposition.

\section{CPAS Test Sequence}

The CPAS test sequence was to be the nominal sequence with one modification. There was interest in demonstrating the CPAS Gen-1 system with the drogues deploying directly to full open in order to build confidence in the implementation of the CPAS for the Pad Abort 1 flight test where the drogues will not have a reefed stage. This modification was considered acceptable because it would also provide altitude margin for reaching full open on the mains in case we lost more altitude in the earlier phases of the test. The pre-test trajectory prediction had the PTV reaching full open mains at 3,800 ft AGL. In order to prevent overloading the drogues the programmer was disreefed to full open prior to release. Drogue mortar fire was sequenced to be coincident with programmer release. Figure 4 depicts the CPAS test sequence. 
30.7 seconds after PTV release from CPSS the

Programmer parachutes are released by the event sequencer and the Drogue mortars fire
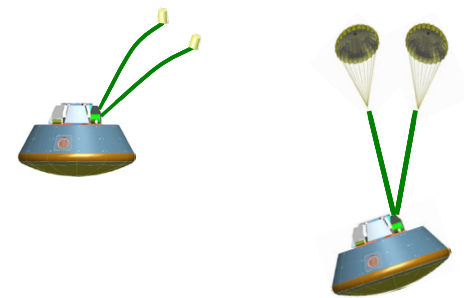

Drogue parachutes

deploy directly to full open

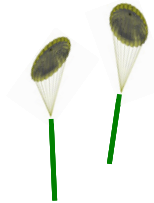

Drawing

Not to Scale

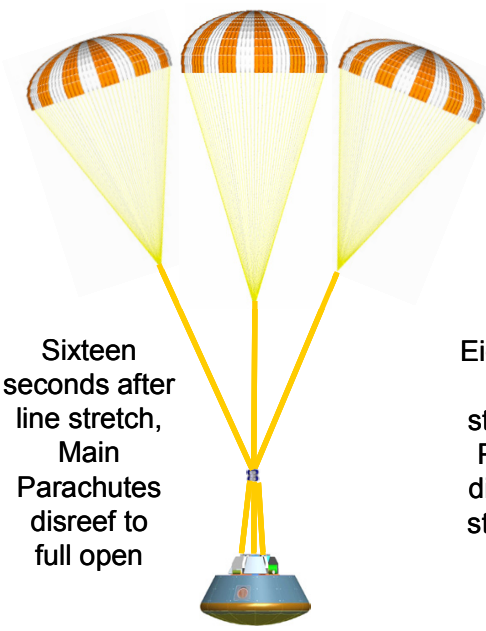

Eight seconds after line stretch, Main Parachutes disreef to $2^{\text {nd }}$ stage reefing of $10 \%$
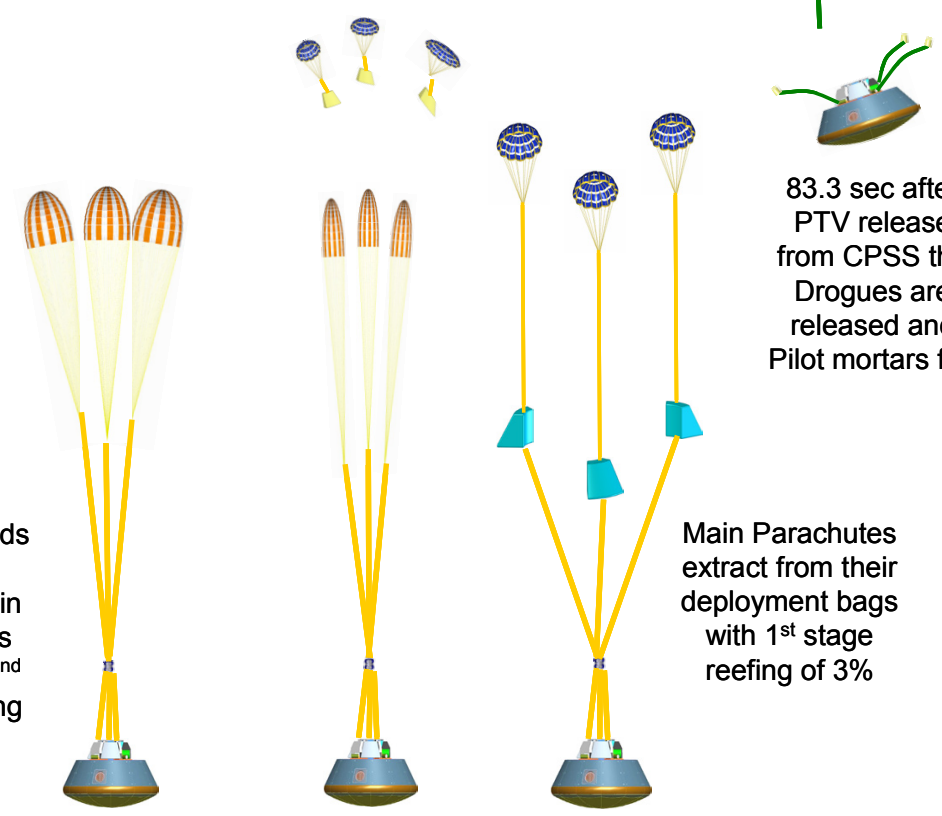

20

$83.3 \mathrm{sec}$ after

PTV release

from CPSS the

Drogues are

released and

Pilot mortars fire

Figure 4. Concept of Operations: CPAS Sequence

\section{CPSS Recovery Phase}

The CPSS also had a sequencer which would release the delayed load transfer 110 seconds after extraction, allowing the $28 \mathrm{ft}$ extraction parachute to deploy the CPSS recovery parachutes. The recovery parachutes consisted of two $15 \mathrm{ft}$ stabilization parachutes and a cluster of three G-11 canopies.

\section{CDT-2 Sequence of Events}

The Test Readiness Review (TRR) was completed with no outstanding actions other than planned day of test activities. All day of test final closeouts were performed as planned. The aircraft took off, climbed to the drop altitude and flew a nominal cold pass. The test article was extracted on a nominal hot pass at the specified release conditions, the extraction was nominal.

The PTV separated from the CPSS in a heat-shield-into-the-wind attitude (angle of attack of $180 \mathrm{deg}$ ). The programmer and stabilization parachutes deployed nominally from their respective deployment bags. The stabilization parachutes, however, did not inflate following initial deployment. The programmer did inflate following deployment., Because the PTV was at an angle of attack of approximately 180 degrees, the programmer inflation load went through the initial side attach point, which caused the PTV to pitch over through apex forward to roughly XX degrees angle of attack. The rotation caused the programmer and stabilization parachute risers to wrap up around the PTV, decreasing the trailing distance of the parachutes with respect to the PTV and pulling the parachutes further into the vehicle wake. The programmer parachute collapsed during this initial pitch oscillation just as the pitch rate approached zero. As the PTV completed the first limit cycle and started the second, the programmer and stabilization attach point repositioned at the planned mission elapsed time to a point above the PTV. Reposition from the initial side attach to the three point attach on the top of the PTV released an additional 16 $\mathrm{ft}$ harness assembly which increased the trailing distance between the parachutes and the PTV. Following reposition, the stabilization parachutes fully inflated for the first time. The programmer parachute, however, did not re-inflate. 
Without an inflated programmer the PTV continued to oscillate in a pitch limit cycle and reached a higher than planned terminal dynamic pressure. The PTV avionics correctly executed the planned test sequence releasing the programmer and stabilization parachutes and mortar-deploying the drogue parachutes at the planned time. Unfortunately, the PTV was inverted when the drogue parachutes started to inflate. As a result, both of the drogue parachute risers were severed as they loaded across the remaining structure from the programmer initial attach point on the side of the PTV. This sequence is represented in snap-shot form in figure 5.

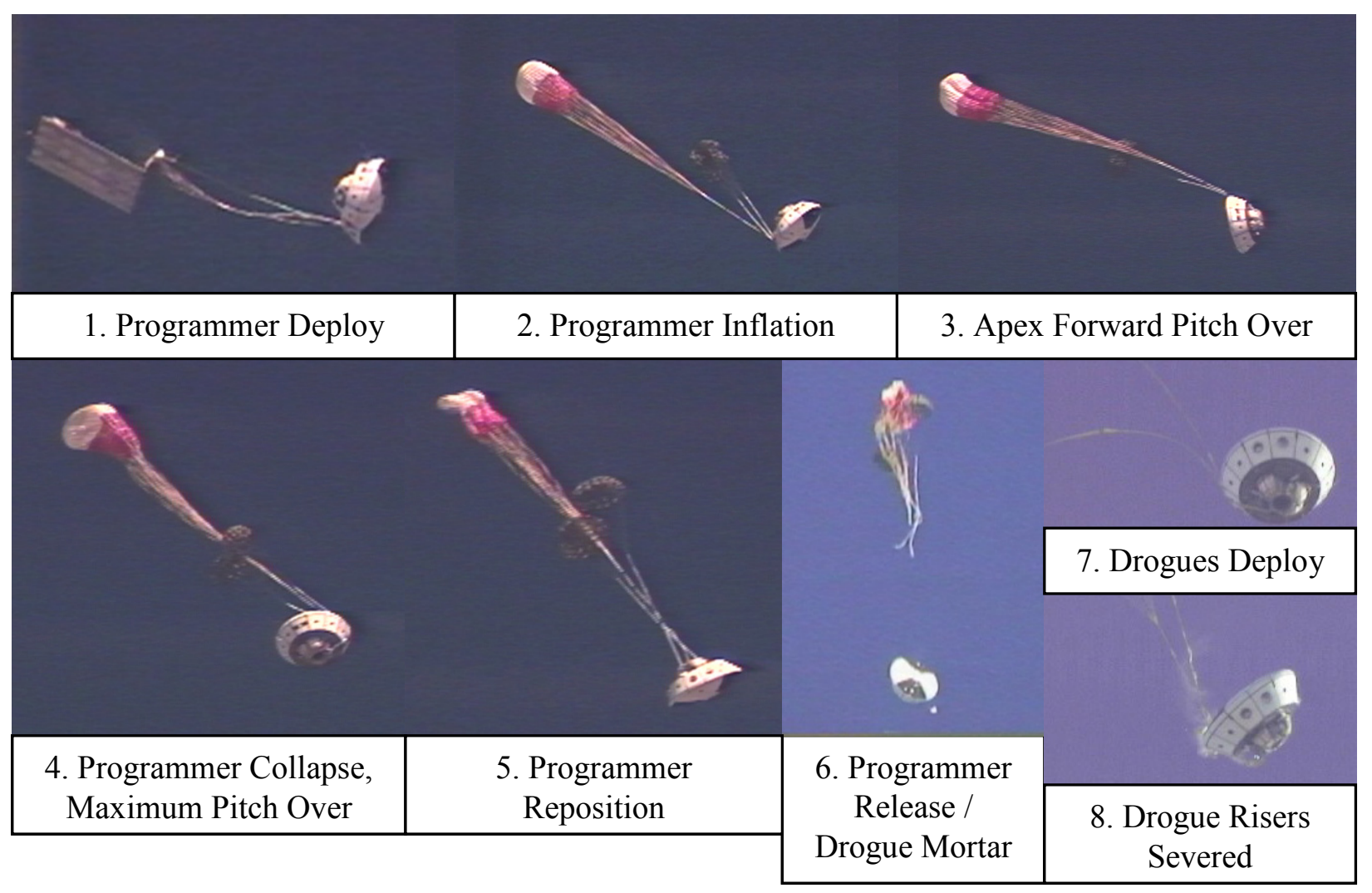

Figure 5. PTV Deploy Sequence through Drogue Risers Severed

The force from the drogues inflating imparted a moment to the PTV which caused the PTV to tumble. The PTV aerodynamics had no way to damp this tumble which resulted in the free-stream dynamic pressure to continue to increase. As the PTV angular rates increased in the free flight, centrifugal forces caused the main parachute retention system to allow a premature deploy of the mains, prior to the pilot mortars being fired. The auto-deployment of the mains resulted in the deployment of the riser and suspension lines while the main deployment bag remained near the vehicle. When the canopy portion reached line stretch and was finally exposed to the air stream, the high dynamic pressure and the enormous relative velocity of this part of the parachute with respect to the vehicle caused the suspension lines to fail, releasing the canopy portion of the parachute. The aforementioned was the failure mechanism for the first two main parachutes. The remaining main parachute reached line stretch before the canopy was deployed. As a result this chute remained attached through the initial inflation. The high dynamic pressure inflation of the last main caused most of the vent region sail area of the canopy to fail, and as a result this main parachute never had enough pressurization to disreef. However, this single flagging main did provide enough drag area to stabilize the PTV into a limit cycle about the normal heat shield forward trim point. The test avionics completed the test sequence, firing the three pilot mortars just before the PTV struck the ground. The PTV was damaged beyond repair. All hardware landed on the drop zone and no individuals were injured as a result of the test.

Following release of the PTV, the CPSS repositioned at the planned time and deployed the recovery parachutes. The CPSS was recovered without damage. 


\section{Mishap Findings}

Per JPR 1700.1, JSC Safety and Health Handbook, a Mishap Investigator (MI) was appointed. The MI findings determined that an Engineering Investigation Team (EIT), not a Mishap Investigation Board (MIB) investigation, was sufficient:

Finding 1: No injuries or illnesses occurred due to the failure

Finding 2: Damage was limited to the test article

Finding 3: Test article debris all landed on the designated drop zone

Finding 4: Test article damage and its cause were anticipated and the test planning, hazard analysis, and test readiness review process characterized and accepted the risk of that particular damage/cause

\section{Engineering Investigation Team Process and Findings}

The CPAS project formed the membership of the EIT. The EIT used a fault tree based process to determine the cause(s) of the test failure. The fault tree was generated with causes beginning with extraction from the aircraft and continuing through to impact. It was decided to define the top tier of the fault tree as "Failed to Achieve Test Conditions". This was justified in that all failures after that point were effects, not causes. A closure sheet was generated for each fault tree branch or individual block. Each closure sheet was reviewed and approved by the EIT leader and EIT technical lead. CPAS parachute experts were asked to review the sheets and concur or provide dissenting opinions. As the final conclusions were developed, the team experts were individually asked for their conclusions and dissenting opinions.

The EIT presented its findings in three reviews. A detailed technical review of the data and findings included representatives from the CPAS technical team, JSC Systems Architecture and Integration Office (EA3) management, EA3 Chief Engineer, JSC Program Engineering Integration Office (EA4) Chief Engineer's office, JSC Structural Engineering (ES) parachute expert, CEV Flight Test Office (FTO), CEV Crew Module Office (CMO), JSC Safety, and a representative from the Marshall Space Flight Center (MSFC) Applied Research and Engineering Sciences (ARES) parachute team. A management review was held including JSC Engineering Directorate (EA) management and the CEV CMO. The final review of the findings was presented to the Constellation Project Configuration Board (CPCB). The conclusions and recommendations presented at all of these reviews were accepted with no dissenting opinions.

\section{A. Data Collected}

The EIT coordinated the post test inspection of the test hardware. The PTV and CPSS structures remained at YPG. The PTV parachutes were sent to Airborne Systems in Santa Ana, CA for inspection. The CPSS parachutes remained at YPG. The extraction parachute system remained at YPG. The avionics systems were sent to JSC. The test videos were recovered by YPG video support.

The failure analysis was based post test inspection of the test articles (hardware and parachutes), review of procedures and test build-up documentation, review of the data available, and expert engineering opinion. The data sources available included: ground to air videos, C-17 on-aircraft video, PTV onboard video, CPSS onboard video, chase helicopter video, CPSS instrumentation (impact recorders, accelerometers, attitudes and rates), PTV instrumentation (impact recorders, accelerometers, attitudes, rates, and static pressure), Winpak measured atmospheric properties, Kineto Tracking Mount Time Space Position Information (PTV trajectory), and PTV based differential GPS trajectory.

\section{B. Failure Cause and Contributing Factors}

The EIT found the test failure was caused by the programmer parachute failing to remain inflated. Two detailed causes for the programmer failure were identified and both are attributed to wake effects.

1) The test design did not consider the effects of large pitch motions changing the trailing distance of the stabilization and programmer parachutes. The decrease in parachute trailing distance was caused by wrapping up the programmer and stabilization parachute risers around and over the PTV. Post test analysis indicated that the programmer trailing distance varied from the intended XX PTV diameters to a minimum of YY PTV diameters. This in turn caused the parachutes to produce less drag due to the lower local dynamic pressure present in the airflow. In addition, the periodic variations in the flow field associated with the limit cycle the vehicle was experiencing were not modeled in the simulations. The performance of the programmer and stabilization chutes was modeled only at the trailing distance associated with a fully inflated parachuted. 
2) The test design did not consider the trailing distance effects of the stabilization parachutes in combination with the PTV on the performance of the programmer parachute. Post test analysis performed by Rice University indicated that the local dynamic pressure at the mouth of the programmer with both the PTV and the stabilization parachutes present was approximately half that with only the PTV as a fore body (Figure6). Rice's time accurate analysis of this flow field in the wake of the combined PTV and inflated stabilization parachutes also showed a pronounced increase in fluctuations of the local dynamic pressure, almost certainly contributing to the programmer collapse and failure to re-inflate.

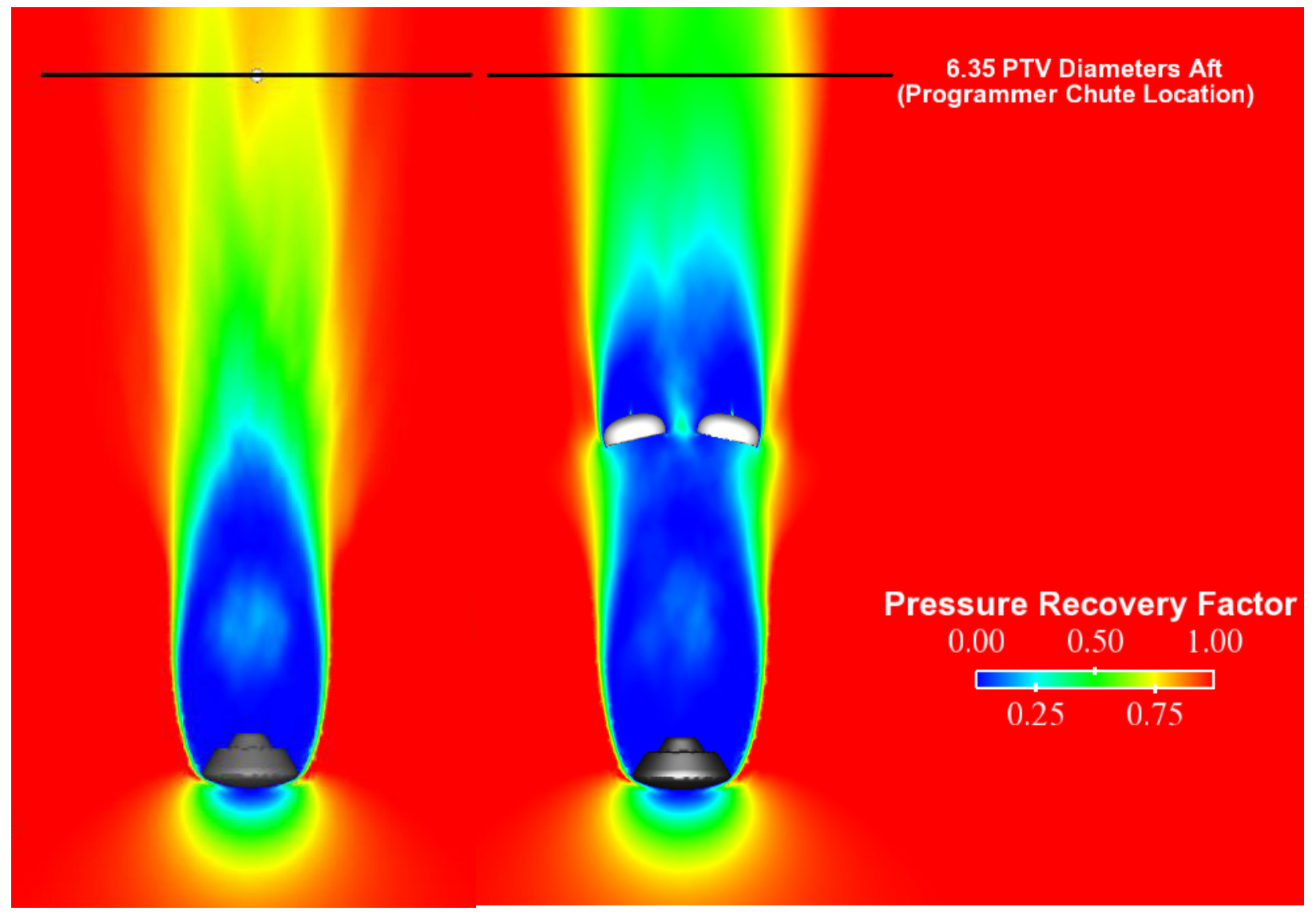

Dr. Tayfun Tezduyar, Rice University

Figure 6. Wake Dynamic Pressure with and without Stabilization Parachutes

The EIT also found three contributing factors.

1) Extraction and separation pre-test models were not robust. This manifested itself in several aspects of the pretest predictions. The CPSS vendor was only able to provide a single PTV release state vector or Initial Condition (IC). In order to account for modeling uncertainties, a Monte Carlo analysis was conducted using dispersions about this IC as inputs. The actual condition experienced in the test, angle of attack around 180 deg at programmer inflation, was not a product of the dispersed trajectory predictions. However, post test simulations showed that this IC should have been acceptable, provided the stabilization parachutes had initially inflated and the programmer had remained inflated. While the modeling did not cause the test failure, it did not accurately predict the actual test conditions and provided the requirement for stabilization parachutes, the EIT determined that the models were a contributing factor.

2) Late completion of the PTV/CPSS separation concept of operations resulted in PTV structural limitations that required reefing the programmer to $20 \%$ in order to limit the inflation loads. Pretest simulations indicated that holding the single point attach on the side of the PTV for six seconds following separation would provide sufficient damping to safely achieve the reposition to the three point attach. Unfortunately, the PTV structure was fully designed and built by the time the final deployment concept of operations generated the requirement for a single point attach. The structural limitations associated with the late 
addition of an initial side point attach, contributed to the selection of the programmer inflation reefing ratio, which the EIT determined was a contributing factor to the test failure.

3) The programmer reefing configuration contributed to the programmer parachute collapse and failure to reinflate. Because the programmer did initially inflate, the reefing ratio alone did not cause the failure. However, once the programmer collapsed during the wrap-up, the reduced air flow into the programmer due to the reefed opening hindered re-inflation. Furthermore, once the stabilization chutes were inflated, their wake effect further hindered programmer re-inflation. When the programmer reefing line was released, the programmer still did not re-inflate, indicating that the reefing ratio alone was not the cause of the failure. Post flight analysis that took into account the high geometric porosity of the Orbiter $40 \mathrm{ft}$ drag parachute suggests that the reefing ratio could have been as low as $14 \%$. Since the reefing line design did not cause the failure, but likely made it worse, it was determined that the reefing line design was a contributor to the test failure.

\section{Conclusion}

Several generic recommendations were driven out of the EIT process that are relevant to the development of a complicated multi-body parachute test as was attempted on CDT-2.

1) Have a completed concept of operations supported by trajectory simulations prior to completion of manufacture of the test article.

2) Do not use multiple parachutes in series at the same time without giving consideration to the combined wake effect on each parachute deployed at any one time.

3) Use parachutes that have been demonstrated at the reefing ratios that will be implemented in the test.

4) Account for the effect the motion of the payload attach point on the effective trailing distance of the parachutes.

5) Make every attempt to simplify the design of the test. As the modeling and analysis become more complicated, the ability to adequately represent the physics of the test becomes increasingly more difficult.

\section{Acknowledgments}

This first attempt to deploy a full-scale CEV boiler plate did not end as anticipated. The CPAS team collectively, including NASA-JSC, NASA-LaRC, Jacobs Engineering, Airborne Systems, Yuma Proving Grounds, the independent parachute experts (Dean Wolf, Roy Fox, and Elsa Hennings), Dr. Tayfun Tezduyar and his team at Rice University, the Low Speed Wind Tunnel at Texas A\&M University, Coleman Aerospace, all invested months of effort to get to the drop zone that morning. As soon as the last test item was on the ground, the team immediately went about recovering the hardware and investigating the causes of the incident. The authors would like to acknowledge the professional behavior of everyone on the team. They set aside their disappointment and concentrated their considerable skills and expertise on the task of investigating the cause of this unfortunate event and learning how to profit from it so we can move forward with the design of the CEV parachute recovery system.

\section{References}

\footnotetext{
${ }^{1}$ Taylor, A. P., Machin, R. A., and Royall, P., "Developing the Parachute System for NASA's Orion - An Overview at Inception", AIAA paper 2007-2577, $19^{\text {th }}$ AIAA Aerodynamic Decelerator Systems Conference, May 2007.

${ }^{2}$ Pete's DSS paper from Munich.
} 